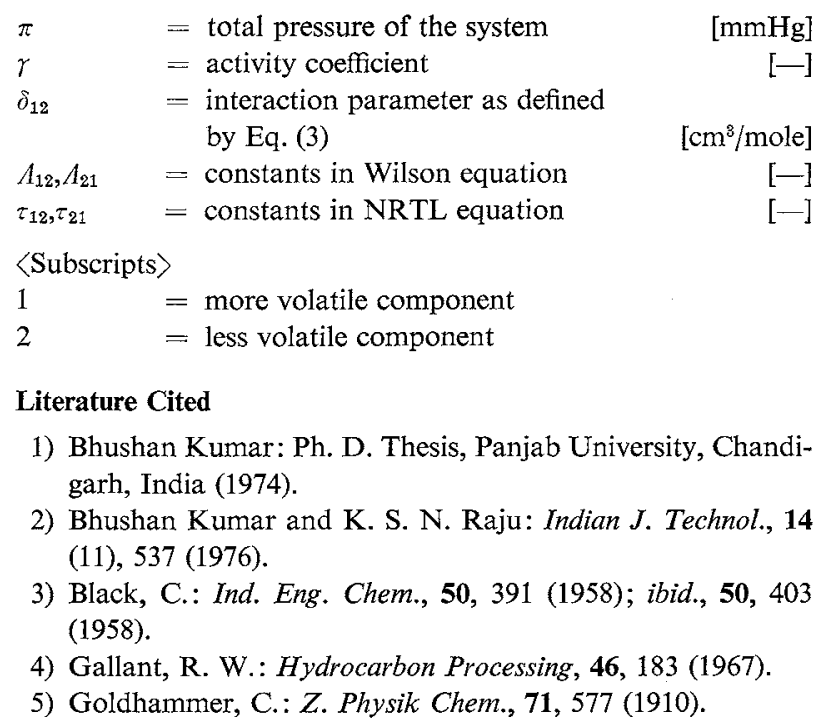

6) Herington, E. F. G.: I. Inst. Petrol., 37, 457 (1951).

7) Lange, N. A. Ed.: "Handbook of Chemistry", 10th ed., McGraw-Hill, New York (1967).

8) Mittal, S.: M. Sc. Chem. Engg. Thesis, Panjab University, Chandigarh, India (1973).

9) Nagahama, K., I. Suzuki and M. Hirata: J. Chem. Eng. Japan, 4, 1 (1971).

10) Norrish, R. S. and G. H. Twigg: Ind. 'Eng. Chem., 46, 201 (1954).

11) O'Connell, J. P. and J. M. Prausnitz: Ind. Eng. Chem., Process Des. Dev., 6, 245 (1967).

12) Renon, H. and J. M. Prausnitz: AIChE J., 14, 135 (1968).

13) Thek, R. E. and L. I. Stiel: ibid., 12, 599 (1966); ibid., 13, 626 (1967).

14) Timmermans, J.: "Physico-Chemical Constants of Pure Organic Compounds", Vol. II, Elsevier, Amsterdam (1965).

15) Weast, R. C. Ed.: "Handbook of Chemistry and Physics", 50th ed., The Chemical Rubber Co. (1969/70).

16) Wilson, G. M.: J. Am. Chem. Soc., 86, 127 (1964).

\title{
APPLICATION OF THE PERTURBATION THEORY TO VAPOR-LIQUID EQUILIBRIA OF SYSTEMS CONTAINING A POLAR SUBSTANCE
}

\author{
Hirokatsu MASUOKA, Chiaki YOKOYAMA, Yasuhiko ARAI and Shozaburo SAITO \\ Department of Chemical Engineering, Tohoku University, Sendai 980
}

In a previous paper ${ }^{4}$, it was shown that the perturbation theory of Barker-Henderson in conjunction with the conformal solution theory proposed by Mansoori and Leland ${ }^{3}$ is applicable to the correlation of vapor-liquid equilibria of systems containing ammonia. In the present study, the perturbation theory has been further applied to systems containing a polar substance other than ammonia. The vaporliquid equilibria of the binary system consisting of a nonpolar substance and a polar substance (acetone, ethyl ether, methyl ethyl ketone or methyl acetate) were calculated by the same procedure as reported previously.

The pair-potential energy-function used is the Lennard-Jones (12-6) type, described in the previous paper:

$$
u(r)=4 \varepsilon\left[\left(\frac{\sigma}{r}\right)^{12}-\left(\frac{\sigma}{r}\right)^{6}\right]
$$

where $\varepsilon$ and $\sigma$ are temperature-dependent potential parameters and are defined as follows:

Received June 2, 1977. Correspondence concerning this article should be addressed to S. Saito. Y. Arai is now at Dept. of Chem. Eng., Kyushu Univ., Fukuoka 812.

$$
\begin{gathered}
\varepsilon=\varepsilon^{\circ} \mathscr{F}^{2} \\
\sigma=\sigma^{\circ} \mathscr{F}^{-1 / 6} \\
\mathscr{F}=1+7 Q^{4} / 20 k T \varepsilon^{\circ}\left(\sigma^{\circ}\right)^{10}+3 Q^{2} \alpha / 4 \varepsilon^{\circ}\left(\sigma^{\circ}\right)^{8}: \\
\text { for nonpolar substance } \\
\mathscr{F}=1+\mu^{4} / 12 k T \varepsilon^{\circ}\left(\sigma^{\circ}\right)^{6}+\mu^{2} \alpha / 2 \varepsilon^{\circ}\left(\sigma^{\circ}\right)^{6}: \\
\text { for polar substance }
\end{gathered}
$$

where $\alpha, \boldsymbol{\mu}$ and $\boldsymbol{Q}$ are polarizability, dipole moment, and quadrupole moment, respectively. These parameters were determined by using vapor pressure data and saturated $P-V-T$ relation for pure substances ${ }^{1,7)}$. The values of these parameters for nonpolar substances are given in Table $\mathbf{1}$, where $\alpha$ is arbitrarily assumed to be zero. Figure 1 shows the vapor pressures and saturated volumes for methane calculated with two different sets of parameters. The pairpotential energy function containing the quadrupole moment seems to improve the calculated results. As shown in Fig. 2, the following linear relations were obtained between the reduced potential parameters and the acentric factor:

$$
\varepsilon^{\circ} / k T_{c}=0.734-0.396 \omega
$$




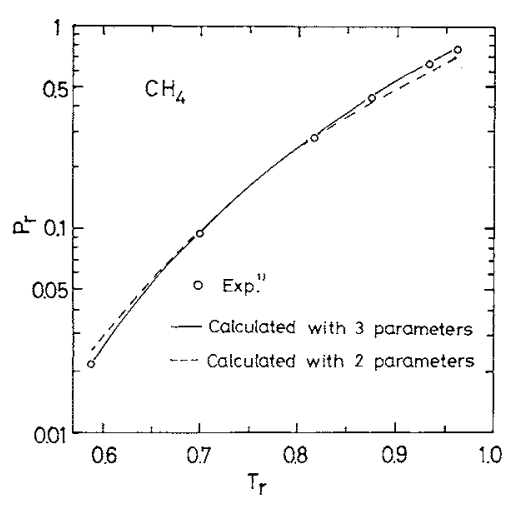

(a) vapor pressure for methane

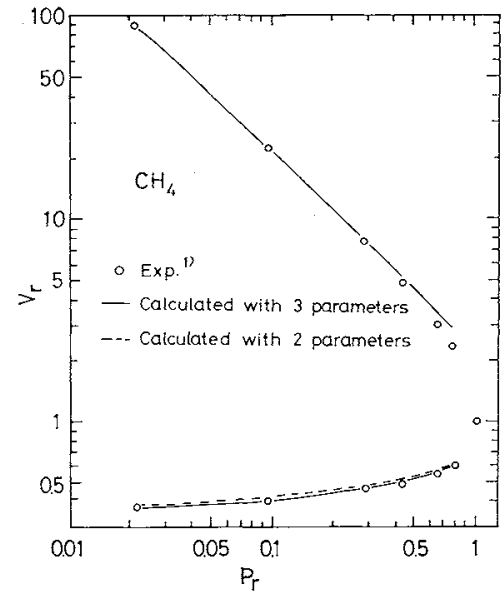

(b) saturated volume for methane

Solid line: calculated with $\varepsilon^{\circ} / k=139.4[\mathrm{~K}], \sigma^{\circ}=3.742[\AA]$ $Q=2.177 \times 10^{-26}\left[\mathrm{erg}^{1 / 2} \mathrm{~cm}^{5 / 2}\right]$

Broken line: calculated with $\varepsilon^{\circ} / k=150.0[\mathrm{~K}], \sigma^{\circ}=3.742[\AA]$ $Q=0\left[\mathrm{erg}^{1 / 2} \mathrm{~cm}^{5 / 2}\right]$

Fig. 1 The calculated and observed vapor pressure and saturated volume for methane

Table 1 Potential parameters for nonpolar and polar substances

(a) nonpolar substances

$\begin{array}{llllcc} & & \varepsilon^{\circ} / k & \sigma^{\circ} & Q \times 10^{26} & \alpha \\ \text { Substance } & \omega & {[\mathrm{K}]} & {[\AA]} & {\left[\operatorname{erg}^{1 / 2} \cdot \mathrm{cm}^{5 / 2}\right]} & {\left[\AA^{3}\right]}\end{array}$

$\begin{array}{lccccc}\text { Methane } & 0.013 & 139.4 & 3.742 & 2.177 & - \\ \text { Ethylene } & 0.089 & 197.6 & 4.125 & 3.948 & - \\ \text { Ethane } & 0.105 & 211.3 & 4.298 & 4.630 & - \\ \text { Propylene } & 0.143 & 247.0 & 4.567 & 6.253 & - \\ \text { Propane } & 0.152 & 249.1 & 4.778 & 7.082 & - \\ \text { n-Butane } & 0.201 & 278.3 & 5.208 & 9.837 & - \\ \text { n-Pentane } & 0.252 & 300.6 & 5.596 & 12.82 & - \\ \text { n-Hexane } & 0.290 & 311.0 & 5.885 & 15.69 & - \\ \text { Nitrogen } & 0.040 & 90.90 & 3.610 & 1.745 & - \\ \text { Carbon monoxide } & 0.041 & 95.65 & 3.614 & 1.823 & - \\ \text { Carbon dioxide } & 0.225 & 196.2 & 3.744 & 3.711 & -\end{array}$

(b) polar substances

\begin{tabular}{lccccc}
$\quad$ Substance & $\omega$ & $\begin{array}{c}\varepsilon^{\circ} / k \\
{[\mathrm{~K}]}\end{array}$ & $\begin{array}{c}\sigma^{\circ} \\
{[\AA]}\end{array}$ & $\begin{array}{c}\boldsymbol{\mu} \times 10^{13} \\
{\left[\mathrm{erg}^{1 / 2} \cdot \mathrm{cm}^{3 / 2}\right]}\end{array}$ & $\begin{array}{c}\alpha \\
\left.\AA^{3}\right]\end{array}$ \\
\hline $\begin{array}{l}\text { Acetone } \\
\text { Methyl ethyl }\end{array}$ & 0.318 & 313.0 & 4.932 & 2.822 & 5.354 \\
ketone & 0.337 & 352.0 & 5.390 & 3.180 & 7.578 \\
$\begin{array}{l}\text { Ethyl ether } \\
\text { Methyl acetate }\end{array}$ & 0.230 & 299.2 & 5.348 & 3.008 & 4.313 \\
\hline
\end{tabular}

$$
\begin{aligned}
& \sigma^{\circ} /\left(V_{c} / N_{A}\right)^{1 / 3}=0.678+0.0762 \omega \\
& Q^{4} / k T_{c} \varepsilon^{\circ}\left(\sigma^{\circ}\right)^{10}=0.0693+1.062 \omega
\end{aligned}
$$

The values of four parameters for polar substances are also given in Table 1. For polar substances, however, these values could not be correlated with a characteristic parameter such as the acentric factor.

Application of the Barker-Henderson perturbation theory to the mixture was performed in conjunction with the conformal solution theory of Mansoori and Leland. According to the conformal solution theory, the intermolecular potential parameters of the hypothetical pure substance, which possesses the same properties as the mixture, are given by the following mixing rules:
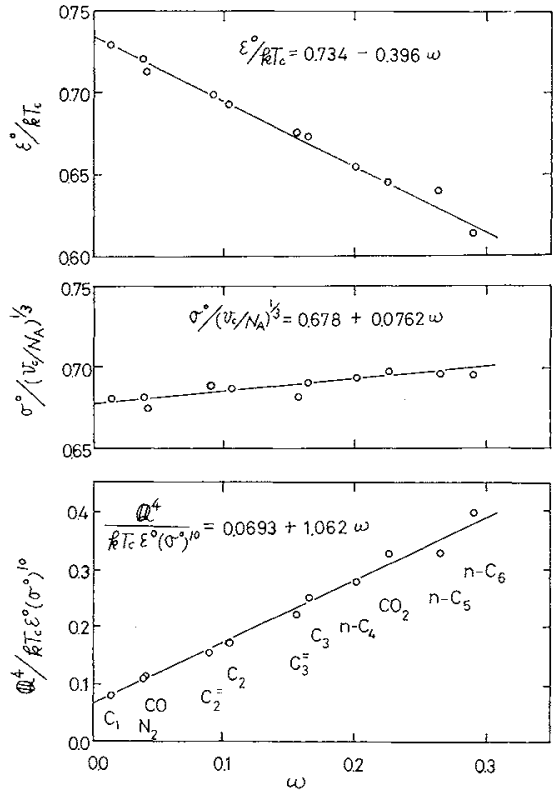

Fig. 2 Correlation of potential parameters

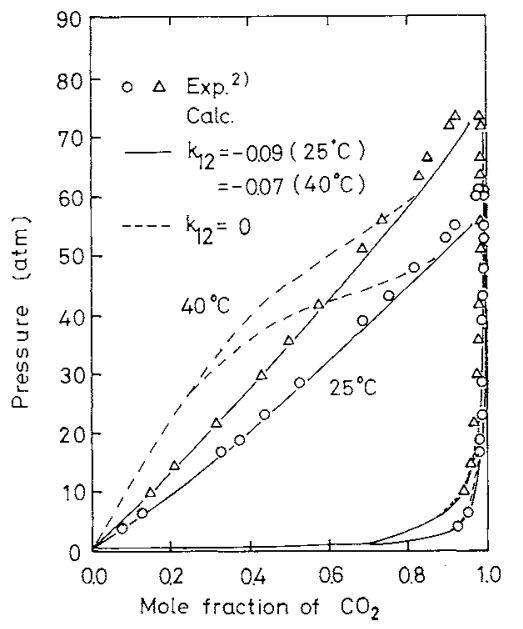

Fig. 3 Vapor-liquid equilibria for the carbon dioxide-acetone system

$$
\begin{aligned}
\tilde{\sigma}^{3} & =\left[\sum_{i=1}^{m} \sum_{j=1}^{m} x_{i} x_{j} \sigma_{i j}^{3} \varepsilon_{i j}\right]^{2} / \sum_{i=1}^{m} \sum_{j=1}^{m} x_{i} x_{j} \sigma_{i j}^{3} \varepsilon_{i j}^{2} \\
\bar{\varepsilon} & =\left[\sum_{i=1}^{m} \sum_{j=1}^{m} x_{i} x_{j} \sigma_{i j}^{3} \varepsilon_{i j}\right] / \bar{\sigma}^{3} \\
\sigma_{i j} & =\left(\sigma_{i i}+\sigma_{j j}\right) / 2 \\
\varepsilon_{i j} & =\left(1-k_{i j}\right) \sqrt{\varepsilon_{i i} \varepsilon_{j j}}
\end{aligned}
$$

where $k_{i j}$ is a binary-interaction parameter which is generally determined experimentally.

By using the above mixing rules, vapor-liquid equilibria were calculated for nine binary systems containing a polar substance using the same procedure as described in the previous paper. Comparisons of calculated and experimental vapor-liquid equilibria for three binary systems are shown in Figs. 3 to $\mathbf{5}$. While the dew-point line is not so sensitive to the binary interaction parameter, $k_{12}$, the introduction of $k_{12}$ can effectively correct the bubble-point line. As 


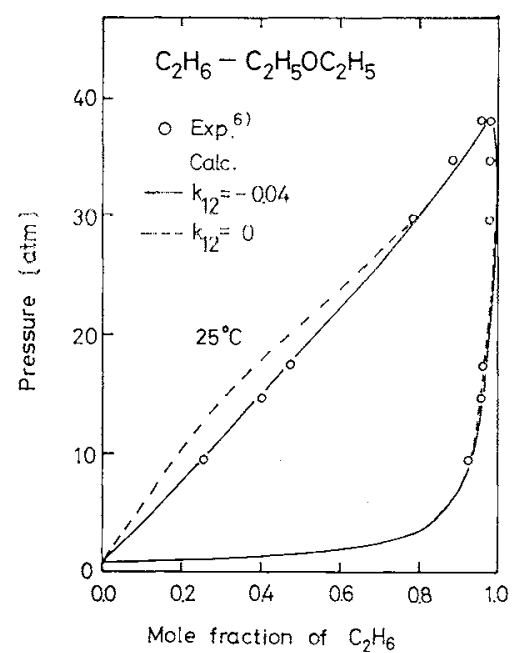

Fig. 4 Vapor-liquid equilibria for the ethane-ethyl ether system

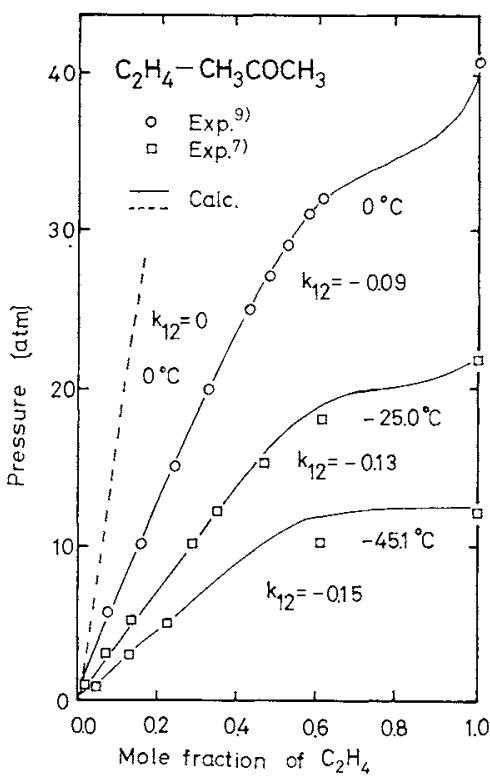

Fig. 5 Solubility of ethylene in acetone

Table 2 Values of $\boldsymbol{k}_{12}$ for binary mixture containing polar substance

\begin{tabular}{|c|c|c|}
\hline $\begin{array}{l}\text { System } \\
\text { (1)-(2) }\end{array}$ & $\begin{array}{c}\text { Temp. } \\
{\left[{ }^{\circ} \mathrm{C}\right]}\end{array}$ & $k_{12}$ \\
\hline ethylene-acetone & $\begin{array}{r}-45.0^{7)} \\
-25.0^{7)} \\
0.0^{9)}\end{array}$ & $\begin{array}{l}-0.15 \\
-0.13 \\
-0.09\end{array}$ \\
\hline ethylene-methyl ethyl ketone $e^{s)}$ & 0.0 & -0.14 \\
\hline ethylene-methyl acetate ${ }^{9)}$ & 0.0 & -0.11 \\
\hline ethane-acetone $e^{\theta)}$ & 25.0 & -0.04 \\
\hline ethane-methyl acetate $\left.{ }^{\theta}\right)$ & 25.0 & -0.01 \\
\hline ethane-ethyl ether ${ }^{\theta)}$ & 25.0 & -0.04 \\
\hline \multirow[t]{2}{*}{ carbon dioxide-acetone ${ }^{2)}$} & 25.0 & -0.09 \\
\hline & 40.0 & -0.07 \\
\hline \multirow[t]{2}{*}{ carbon dioxide methyl acetate ${ }^{f)}$} & 25.0 & -0.12 \\
\hline & 40.0 & -0.10 \\
\hline \multirow[t]{2}{*}{ carbon dioxide-ethyl ether ${ }^{5)}$} & 25.0 & -0.01 \\
\hline & 40.0 & 0.01 \\
\hline
\end{tabular}

shown in Table 2, and Figs. 3 to $5, k_{12}$ is temperaturedependent, and it seems that the higher the temperature, the larger the $k_{12}$ value needed. Figure 3 also shows that the calculated results tend to be poor near the critical temperature of solute gas. This may be ascribed to the fact that the equation of state used here for the pure substances is poor in the critical region.

In summary, the perturbation theory of BarkerHenderson in conjunction with the conformal solution theory was found to be useful for correlating vaporliquid equilibria of systems containing polar substances, except in the critical region.

\section{Nomenclature}

$\begin{array}{llr}k & =\text { Boltzmann constant } & {[\mathrm{erg} / \mathrm{K}]} \\ k_{i j} & =\text { binary interaction parameter } & {[--]} \\ N_{A} & =\text { Avogadro's number } & {[1 / \mathrm{mol}]} \\ Q & =\text { quadrupole moment } & {\left[\mathrm{erg}^{1 / 2} \cdot \mathrm{cm}^{5 / 2}\right]} \\ r & =\text { intermolecular distance } & {[\AA]} \\ T & =\text { temperature } & {[\mathrm{K}]} \\ u(r) & =\text { pair-potential energy-function } & {[\mathrm{erg}]} \\ x & =\text { mole fraction } & {[-]} \\ V & =\text { molar volume } & {\left[\mathrm{cm}^{3} / \mathrm{mol}^{2}\right]} \\ \alpha & =\text { polarizability } & \\ \varepsilon & =\text { well depth in potential function } & {\left[\AA^{3}\right]} \\ \mu & =\text { dipole moment } & {\left[\mathrm{erg}^{3}\right]} \\ \sigma & =\text { collision diameter } & {[\AA]} \\ \omega & =\text { Pitzer's acentric factor } & {[--]} \\ \langle\text { Superscripts and subscripts }\rangle & \\ i, j & =\text { component } i \text { and } j \\ c & =\text { critical property } \\ - & =\text { hypothetical pure substance } & \\ 0 & =\text { pure substance property }\end{array}$

\section{Literature Cited}

1) Canjar, L. N. and F. S. Manning: "Thermodynamic Properties and Reduced Correlations for Gases", Gulf Pub. Co., Houston, Texas (1967).

2) Katayama, T., K. Ohgaki, G. Maekawa, M. Goto and T. Nagano: J. Chem. Eng. Japan, 8, 89 (1975).

3) Mansoori, G. A. and T. W. Leland, Jr.: Faraday Trans. II, 68, 320 (1972).

4) Masuoka, H., Y. Arai and S. Saito: J. Chem. Eng. Japan, 10, 171 (1977).

5) Ohgaki, K. and T. Katayama: J, Chem. Eng. Data., 20, 264 (1975).

6) Ohgaki, K., F. Sano and T. Katayama: ibid., 21, 55 (1976).

7) Shenderei, E. R., Ya. D. Zel'venskii and F. P. Ivanovskii: Zh. Fiz. Khim., 36, 801 (1962).

8) Timmermans, J.: "Physico-Chemical Constants of Pure Organic Compounds", Elsevier, New York (1950).

9) Yorizane, M., S. Sadamoto, S. Yoshimura, H. Masuoka and H. Nakayuki: Preprints of Okayama Meeting of The Soc. of Chem. Engrs., Japan, p. 25, Okayama (1972).

(Presented at the 10th Autumn Meeting of The Soc. of Chem. Engrs., Japan, at Nagoya, 1976.) 